\title{
Contrasting Effects of Dopamine and Dobutamine on Myocardial Release of Norepinephrine during Acute Myocardial Infarction
}

\author{
Seinosuke Kawashima, M.D., John Combes, M.D., \\ Chang-seng Liang, M.D., Ph.D., Catherine Mesner, \\ and William B. Hood, Jr., M.D.
}

\section{SUmmary}

The effects of dopamine and dobutamine on release of norepinephrine from normal and ischemic myocardium were compared in 2 groups of open-chest anesthetized dogs. Both agents were infused intravenously at a rate of $10 \mu \mathrm{g} / \mathrm{Kg} / \mathrm{min}$ for 2 hours, beginning $40 \mathrm{~min}$ after snare occlusion of the left anterior descending coronary artery. There were no major differences in hemodynamic responses between the 2 groups. Blood samples were taken simultaneously from the aorta, coronary sinus and the cardiac vein that ran parallel to the left anterior descending coronary artery before and after coronary artery occlusion. Plasma norepinephrine increased $40 \mathrm{~min}$ after the occlusion, with a net efflux in both coronary sinus and cardiac venous blood. Dopamine caused further increases in plasma norepinephrine. At 20 min after the beginning of dopamine infusion the coronary sinus concentration $(4.09 \pm 1.36 \mathrm{ng} / \mathrm{ml})$ was significantly greater than the arterial concentration $(2.84 \pm$ $0.87 \mathrm{ng} / \mathrm{ml}$ ). This transcardiac difference disappeared during continuous infusion 2 hours after coronary artery occlusion. Differences in norepinephrine concentration between the arterial and cardiac venous blood, however, were not significant. In contrast, plasma norepinephrine did not increase during dobutamine infusion in either the ischemic or non-ischemic bed. Thus, the results suggest that while these two agents have similar systemic hemodynamic effects, only dopamine increases myocardial release of norepinephrine from either ischemic or normal myocardium during acute myocardial infarction.

From the Cardiology Research Laboratories, University of Rochester School of Medicine and Dentistry, Rochester, New York, and the Departments of Medicine and Pharmacology, Boston Uni* versity School of Medicine, Boston, Massachusetts, U.S.A.

The study was supported in part by NIH grants HL-30142, HL-30194, HL-30278.

Address for reprint: Chang-seng Liang, M.D., Ph.D., Cardiology Research Laboratories, Box 679, University of Rochester Medical Center, 601 Elmwood Avenue, Rochester, New York 14642, U.S.A.

Received for publication December 27, 1984. 


\section{Additional Indexing Words:}

Myocardial blood flow Coronary artery occlusion

\section{D}

OPAMINE and dobutamine are two commonly used inotropic agents. We have shown recently that both agents are effective in enhancing left ventricular performance during acute myocardial infarction, but only dobutamine reduces infarct size in awake dogs. ${ }^{1,2)}$ The reason for the differences between the two drugs probably is related, at least in part, to the detrimental cardiac effects of norepinephrine released by dopamine. 2) We found that both coronary sinus and arterial norepinephrine concentrations were increased by dopamine infusion, with a net efflux of norepinephrine. ${ }^{2)}$ However, it was not determined whether norepinephrine was preferentially released by dopamine from the ischemic myocardium. The present study was carried out to study further the contrasting effects of dobutamine and dopamine on myocardial release of norepinephrine in acute myocardial infarction. Blood samples were taken for norepinephrine from both the coronary sinus and from the cardiac vein that drained the ischemic myocardium so that the effect of dopamine on both ischemic and non-ischemic myocardium could be compared. Effects of the two drugs on systemic hemodynamics and regional myocardial blood flow also were determined.

\section{Methods}

Adult mongrel dogs weighing 17.3 to $29 \mathrm{Kg}$ were anesthetized with sodium pentobarbital $(30 \mathrm{mg} / \mathrm{Kg}$, iv) and mechanically ventilated with room air using a Harvard respirator (Harvard Apparatus Co., Inc., S. Natick, Massachusetts), maintaining blood gases and $\mathrm{pH}$ within physiological ranges. After the pericardial sac was opened via a left thoracotomy at the fifth intercostal space, Tygon catheters were inserted directly into the main pulmonary artery, left atrium and descending thoracic aorta for measuring blood pressures. A loose silk ligature was placed around the left anterior descending coronary artery distal to the first diagonal branch for subsequent occlusion using a snare. Another silk loop was placed around the cardiac vein that ran parallel to the left anterior descending artery. A catheter, i.d. $2.5 \mathrm{~mm}$, was inserted into the coronary sinus via the right atrial appendage. In addition, a short PE 50 catheter was introduced into the coronary sinus catheter and advanced into the cardiac vein to a site proximal to the silk ligature. These two catheters were used for sampling coronary sinus and cardiac venous blood for norepinephrine measurements. The heart was cradled in the pericardial sac and covered with a warm moist gauze pad throughout the 
experiment. A femoral vein was cannulated for drug infusion. Heparin (200 units $/ \mathrm{Kg}$ ) was administered intravenously to prevent blood clotting.

\section{Measurements}

The catheters were connected to Statham $\mathrm{P} 23 \mathrm{Db}$ pressure transducers and a Brush 480 recorder (Gould, Inc., Instrument Systems Division, Cleveland, Ohio). Cardiac output was measured by the dye dilution method (Cardio-Green; Hynson, Westcott and Dunning, Inc., Baltimore, Maryland) with a Gilford model 140 cardiac output system (Gilford Instrument Laboratories, Inc., Oberlin, Ohio). Heart rate was calculated from the electrocardiogram. Regional myocardial blood flows were measured by a radioactive microsphere method. ${ }^{3,4)}$ Radioactive microspheres (New England Nuclear, Boston, Massachusetts), $15 \pm 3 \mu \mathrm{m}$ in diameter and labeled with cerium-141, ruthenium-103, niobium-95 and scandium-46 were suspended in a $10 \%$ dextran solution containing $0.01 \%$ Tween 80 . After adequate sonication and agitation on a Vortex mixer, the microspheres were injected into the left atrium, followed by a flush of $10 \mathrm{ml}$ of normal saline. A reference arterial blood sample was withdrawn at a rate of $7.75 \mathrm{ml} / \mathrm{min}$ beginning $10 \mathrm{sec}$ before the injection and continuing $80 \mathrm{sec}$ thereafter. For each flow determination, approximately 1 million microspheres were injected prior to coronary artery ligation, whereas 2-3 million microspheres were injected after the occlusion. At the end of the experiment, dogs were sacrificed with a lethal dose of sodium pentobarbital and the hearts removed. The left ventricle was cut transversely into 7-8 $\mathrm{mm}$ thick slices. Each slice was divided into 4 to 9 transmural pieces which were then subdivided into endocardial and epicardial halves. The tissue and blood samples were weighed and counted for radioactivity on a Packard gamma spectrometer and multichannel analyzer (Packard Instrument Co., Inc., Downers Grove, Illinois). The radioactivity of each isotope was corrected for background and cross activity from other isotopes was subtracted, using the method of simultaneous equations. Coefficients from these equations were obtained by using the response to a given isotope on each of the channels associated with the other isotopes. Regional myocardial blood flow was calculated on a LSI 11/23 minicomputer (Digital Computer Corp., Maynard, Massachusetts) using the following formula:

Myocardial blood flow $(\mathrm{ml} / 100 \mathrm{~g} / \mathrm{min})$ $=\frac{(\text { counts } / \text { gram tissue }) \times(\text { reference blood flow }, \mathrm{ml} / \mathrm{min}) \times 100}{\text { counts in reference blood sample }}$

Left ventricular transmural segments were grouped into four regions according to their endocardial blood flows after coronary occlusion. Transmural segments with endocardial flows less than $25 \mathrm{ml} / 100 \mathrm{~g} / \mathrm{min}$ were classi- 
fied as severely ischemic areas, whereas segments with endocardial flows of 25 to $50 \mathrm{ml} / 100 \mathrm{~g} / \mathrm{min}$ and 50 to $75 \mathrm{ml} / 100 \mathrm{~g} / \mathrm{min}$ were designated as moderately and mildly ischemic areas, respectively. Areas with endocardial flows greater than $75 \mathrm{ml} / 100 \mathrm{~g} / \mathrm{min}$ were classified as non-ischemic areas.

\section{Experimental protocol}

Sixtcen dogs were assigned randomly and equally to 2 groups that received either dobutamine $(10 \mu \mathrm{g} / \mathrm{Kg} / \mathrm{min})$ or dopamine $(10 \mu \mathrm{g} / \mathrm{Kg} / \mathrm{min})$. The remainder of the protocol was identical in the 2 groups. The protocol entailed a 20 min control period and a 2 hour period of coronary artery occlusion produced by the snare ligature previously placed around the mid left anterior descending coronary artery. Beginning $40 \mathrm{~min}$ after the onset of coronary artery occlusion, dobutamine or dopamine was administered at a rate of $0.19 \mathrm{ml} / \mathrm{min}$ throughout the remainder of the experiment. Systemic hemodynamics were obtained in triplicate during the control period and at 40,60 and $120 \mathrm{~min}$ after coronary artery occlusion. The average values were treated statistically and are reported in "Results". Myocardial blood flow and plasma norepinephrine measurements were made immediately before coronary artery occlusion and at 40 (immediately before the drug infusion), 60 and 120 min after occlusion. Blood samples were taken simultaneously from the aorta, coronary sinus and cardiac vein for norepinephrine determinations, using a radioenzymatic method") with Cat-A-Kits (Upjohn Co., Kalamazoo, Michigan). During blood sampling the silk loop placed around the cardiac vein was tied transiently so that the venous blood from ischemic myocardium (in cardiac vein) would not be mixed with that from nonischemic myocardium (in coronary sinus).

\section{Statistics}

The experimental results are given as mean $\pm \mathrm{SE}$. The statistical significance of the difference among the 2 groups was determined by two-way analysis of variance with repeated measures. ${ }^{6}$ ) Dunnett's test ${ }^{7)}$ was used to determine the significance of the difference between the pre-infusion value and the serial measurements after the infusion of each drug. Student's ttest was used to analyze the difference between two means. The difference was considered significant if $\mathrm{p}<0.05$.

\section{Results}

Of the 16 dogs studied, 2 dogs died of ventricular fibrillation shortly after coronary artery occlusion. Thus, the results were derived from the remaining 14 dogs; 8 dogs received dopamine and 6 dogs dobutamine. These 2 groups did not differ in baseline hemodynamic or norepinephrine measure- 
Table I. Effects of Dopamine and Dobutamine on Systemic Hemodynamics during Acute Myocardial Infarction

\begin{tabular}{l|l|c|c|c}
\hline & $\begin{array}{c}\text { Heart rate } \\
\text { (beats/min) }\end{array}$ & $\begin{array}{c}\text { Aortic mean } \\
\text { blood pressure } \\
(\mathrm{mmHg})\end{array}$ & $\begin{array}{c}\text { Left atrial } \\
\text { mean pressure } \\
(\mathrm{mmHg})\end{array}$ & $\begin{array}{c}\text { Cardiac output } \\
(\mathrm{L} / \mathrm{min})\end{array}$ \\
\hline
\end{tabular}

Group 1. Dopamine infusion $(n=8,22 \pm 1 \mathrm{Kg})$

\begin{tabular}{l|l|l|l|l} 
Control & $158 \pm 11$ & $106 \pm 8$ & $7.0 \pm 0.5$ & $2.35 \pm 0.29$ \\
Occlusion & $144 \pm 9$ & $100 \pm 7$ & $8.6 \pm 0.6$ & $2.12 \pm 0.24$ \\
$1 \mathrm{hr}$ & $175 \pm 6^{*}$ & $109 \pm 11$ & $7.3 \pm 0.5$ & $3.10 \pm 0.36^{*}$ \\
$2 \mathrm{hrs}$ & $178 \pm 8^{*}$ & $105 \pm 9$ & $7.5 \pm 0.5$ & $2.74 \pm 0.54$
\end{tabular}

Group 2. Dobutamine infusion $(n=6,21 \pm 1 \mathrm{Kg})$

\begin{tabular}{l|l|l|l|r} 
Control & $143 \pm 6$ & $93 \pm 6$ & $7.2 \pm 0.8$ & $2.38 \pm 0.27$ \\
Occlusion & $144 \pm 10$ & $92 \pm 5$ & $8.1 \pm 0.5$ & $2.34 \pm 0.28$ \\
$1 \mathrm{hr}$ & $178 \pm 12^{*}$ & $93 \pm 5$ & $7.5 \pm 0.5$ & $2.56 \pm 0.28$ \\
$2 \mathrm{hrs}$ & $184 \pm 10^{*}$ & $94 \pm 5$ & $7.5 \pm 0.4$ & $2.17 \pm 0.14$
\end{tabular}

Values are mean \pm SE. The number of experiments and body weights of the dogs are given in parentheses after each subheading. The control values were obtained before coronary artery occlusion, whereas the occlusion, $1 \mathrm{hr}$ and $2 \mathrm{hrs}$ values were taken $40 \mathrm{~min}, 1$ hour and 2 hours after coronary artery occlusion. Coronary artery occlusion did not produce significant changes in any of these parameters. Asterisks indicate values that differ from the occlusion values at $\mathrm{p}<0.05$.

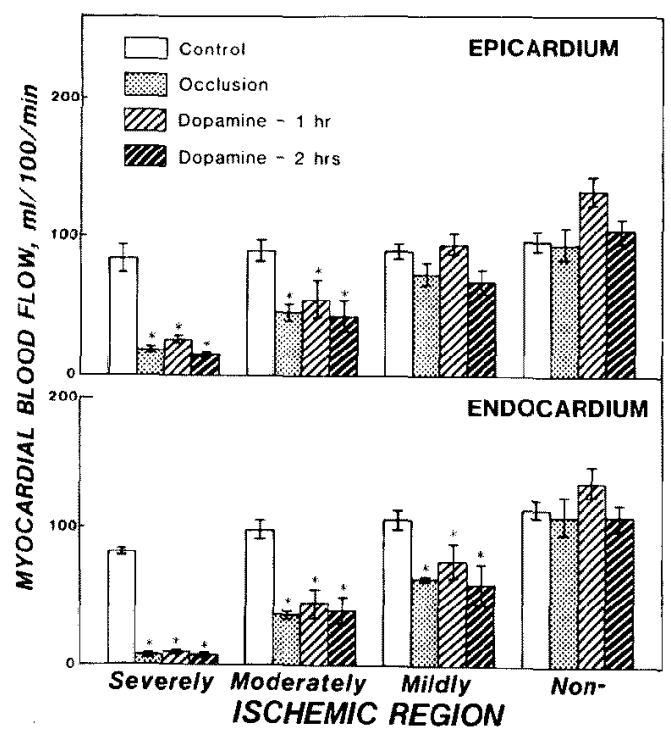

Fig. 1. Effects of coronary artery occlusion and dopamine infusion on epicardial and endocardial blood flows in 8 dogs. The occlusion and dopamine values were obtained at $40 \mathrm{~min}, 1$ hour and 2 hours after coronary artery occlusion. Bars show SE. Asterisks indicate values that differ from the control at $\mathrm{p}<0.05$. 
ments. Coronary artery occlusion produced no significant immediate changes in heart rate, mean aortic blood pressure, mean left atrial pressure and cardiac output in either group (Table I). Dobutamine and dopamine infusion increased heart rate, but did not change either mean aortic pressure or left atrial pressure. Cardiac output also did not change following dobutamine infusion, but a transient small increase in cardiac output was produced by dopamine.

The effects of coronary artery occlusion and drug infusions on myocardial blood flow are shown in Figs. 1 and 2. Dopamine infusion produced no significant changes in either ischemic or non-ischemic myocardial blood flow (Fig. 1). Dobutamine infusion also did not change myocardial blood flow in severely ischemic myocardium, but it increased epicardial flow in the mildly ischemic area and both endocardial and epicardial flows in the nonischemic myocardium (Fig. 2). Dobutamine infusion also increased endocardial flow in the mildly ischemic region and epicardial flow in the moderately ischemic region toward the control values; however, these values obtained during dobutamine infusion did not differ significantly from the pre-infusion occlusion values.

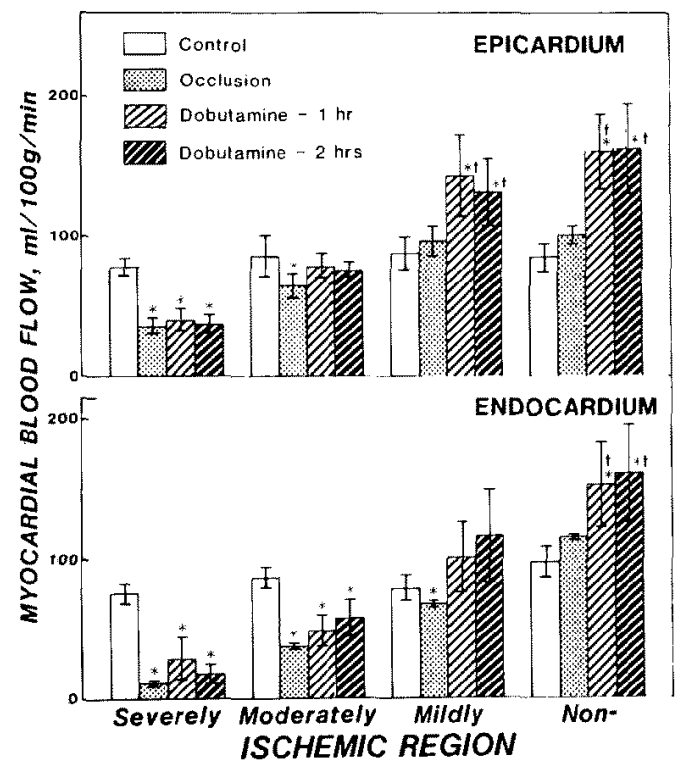

Fig. 2. Effects of coronary artery occlusion and dobutamine infusion on epicardial and endocardial blood flows in 6 dogs. The occlusion and dobutamine values were obtained at $40 \mathrm{~min}, 1$ hour and 2 hours after coronary artery occlusion. Bars show SE. Asterisks indicate values that differ from the control at $\mathrm{p}<0.05$, whereas the dagger signs indicate values that differ from the occlusion values at $\mathrm{p}<0.05$. 


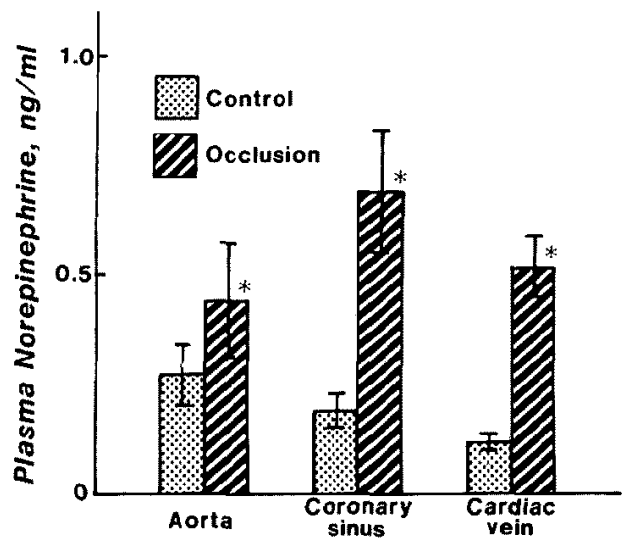

Fig. 3. Effects of coronary artery occlusion on plasma norepinephrine concentration in aortic, coronary sinus and cardiac venous blood. Bars show $\mathrm{SE}$. Asterisks indicate values that differ from the control at $\mathrm{p}<0.05$.

Table II. Effect of Dopamine and Dobutamine on Plasma Norepinephrine during Acute Myocardial Infarction

\begin{tabular}{|c|c|c|c|}
\hline & \multicolumn{3}{|c|}{ Plasma norepinephrine concentration ( $\mathrm{ng} / \mathrm{ml})$} \\
\hline & Aortic & Coronary sinus & Cardiac vein \\
\hline \multicolumn{4}{|c|}{ Group 1. Dopamine infusion } \\
\hline Occlusion & $0.48 \pm 0.14$ & $0.67 \pm 0.15$ & $0.37 \pm 0.10$ \\
\hline $1 \mathrm{hr}$ & $2.84 \pm 0.87 *$ & $4.09 \pm 1.36 * \dagger$ & $3.65 \pm 1.44 *$ \\
\hline $2 \mathrm{hrs}$ & $3.09 \pm 0.79^{*}$ & $3.07 \pm 1.37 *$ & $3.02 \pm 1.03 *$ \\
\hline \multicolumn{4}{|c|}{ Group 2. Dobutamine infusion } \\
\hline Occlusion & $0.40 \pm 0.22$ & $0.70 \pm 0.26$ & $0.57 \pm 0.12$ \\
\hline $1 \mathrm{hr}$ & $0.42 \pm 0.15$ & $0.47 \pm 0.19$ & $0.35 \pm 0.07$ \\
\hline $2 \mathrm{hrs}$ & $0.59 \pm 0.14$ & $0.49 \pm 0.15$ & $0.52 \pm 0.12$ \\
\hline
\end{tabular}

Values are mean $\pm \mathrm{SE}$. The number of experiments and body weights of the dogs are the same as in Table I. The occlusion, $1 \mathrm{hr}$ and $2 \mathrm{hrs}$ values were taken at $40 \mathrm{~min}, 1$ hour and 2 hours after coronary artery occlusion. Asterisks indicate values that differ from the occlusion values at $\mathrm{p}<0.05$, whereas the dagger sign indicates that the value differs from the corresponding arterial value at $\mathrm{p}<0.05$.

Coronary artery occlusion increased norepinephrine concentrations in arterial, coronary sinus and cardiac venous blood (Fig. 3). The increase was significantly greater in the coronary sinus and cardiac venous blood than in the arterial blood, but there was no difference between the coronary sinus and cardiac venous blood. Infusion of dopamine caused a marked elevation in plasma norepinephrine (Table II). During the first $20 \mathrm{~min}$ of infusion, the increase was significantly greater in the coronary sinus blood than in the arterial blood, suggesting an initial net release of norepinephrine from the 
heart. The transcardiac difference in norepinephrine concentration disappeared 2 hours after coronary artery occlusion. Unlike dopamine, dobutamine infusion did not produce statistically significant changes in plasma norepinephrine in either the ischemic or non-ischemic bed.

\section{Discussion}

Our present study shows that plasma norepinephrine increases in arterial, coronary sinus and cardiac venous blood after coronary artery occlusion. Arterial catecholamines have been shown to increase immediately after coronary artery occlusion. ${ }^{81-10}$ ) These changes are thought to reflect augmentation of sympathetic neural and adrenomedullary activities.91,11) Sympathetic stimulation of the heart probably is responsible, at least in part, for the net release of norepinephrine into the coronary sinus and cardiac vein after coronary artery occlusion in our experiments. Our study further shows that norepinephrine is not released preferentially from the ischemic myocardium, because norepinephrine efflux did not differ between the coronary sinus and cardiac venous blood. Our results, however, do not exclude the possibility that preferential release of norepinephrine from ischemic myocardium occurs within the first 40 min of myocardial infarction. ${ }^{8}$ The augmented cardiac adrenergic activity has been implicated in causing ventricular fibrillation and mechanical deterioration of the ischemic myocardium. ${ }^{91,12)}$

The present study also confirms our earlier finding's) that dopamine caused further increases in arterial norepinephrine concentration during acute myocardial infarction. This is consistent with the pharmacologic action of dopamine in releasing endogenous norepinephrine from sympathetic nerve endings. ${ }^{13)-15)}$ Our plasma norepinephrine measurements also indicate that during dopamine infusion norepinephrine is largely released from the non-ischemic myocardium and that its release from ischemic myocardium is relatively small, because the arterial and cardiac venous norepinephrine concentrations did not differ significantly. Furthermore, since the aortocoronary venous norepinephrine difference in the dopamine group disappeared 2 hours after coronary occlusion, the myocardial norepinephrine release produced by dopamine is limited. Although the reason for this limited myocardial release of norepinephrine despite the continued elevation of arterial norepinephrine is not clear, it suggests that myocardial norepinephrine stores are limited and that myocardial norepinephrine synthesis lags behind its release during acute myocardial infarction and dopamine infusion.

Heart rate increased significantly during dobutamine and dopamine infusions in our present study. The increases were much greater than those 
observed in awake chronically instrumented dogs. ${ }^{2)}$ This difference in heart rate responses between the two studies probably is related to the use of pentobarbital anesthesia and open-chest surgery in the present study. Other investigators ${ }^{16), 17)}$ also have shown dobutamine caused a greater increase in heart rate in anesthetized dogs than in normal conscious dogs.

Myocardial blood flow increased in both mildly ischemic epicardium and normal endocardial and epicardial regions of the heart during dobutamine infusion. The increase in myocardial blood flow probably was caused by both the metabolically mediated vasodilation resulting from cardiac beta-1 stimulation and the beta-2 receptor mediated coronary vasodilator action of dobutamine. ${ }^{18), 191}$ Our results, however, do not allow us to conclude whether dobutamine increased collateral flow to the ischemic myocardium. Dopamine also has been shown to have a vasodilator property, ${ }^{13)}$ but the absence of increased myocardial blood flow in our experiments suggests that the vasodilator action of dopamine could be offset by either the vasoconstrictor action of endogenously released norepinephrine or by the alpha agonist effect of dopamine, or both.

In summary, dopamine increased arterial norepinephrine concentration and release of norepinephrine from both normal and ischemic myocardium after coronary artery occlusion. In contrast, dobutamine does not exaggerate the systemic and myocardial norepinephrine release during acute myocardial infarction. In addition, only dobutamine increases blood flow to both normal and partly ischemic myocardium. These probably are the mechanisms by which dobutamine improves hemodynamic parameters without increasing the extent of myocardial injury in patients with acute myocardial infarction;20) similar clinical studies with dopamine are lacking.

\section{AcKnowledgments}

The authors wish to thank Samuel Rivers and Jayne Bouldry-Whitin for their technical assistance.

\section{REFERENCES}

1. Liang C-S, Yi JM, Sherman LG, Black J, Gavras H, Hood WB Jr: Dobutamine infusion in conscious dogs with and without acute myocardial infarction. Effects on systemic hemodynamics, myocardial blood flow, and infarct size. Circ Res 49: 170, 1981

2. Maekawa $\mathrm{K}$, Liang C-S, Hood WB Jr: Comparison of dobutamine and dopamine in acute myocardial infarction. Effects of systemic hemodynamics, plasma catecholamines, blood flows and infarct size. Circulation 67: 750, 1983

3. Utley J, Carlson EL, Hoffman JIE, Martinez HM, Buckberg GD: Total and regional myocardial blood flow measurements with $25 \mu, 15 \mu, 9 \mu$, and filtered 1-10 $\ell$ diameter microspheres and antipyrine in dogs and sheep. Circ Res 34: 391, 1974 
4. Liang C-S: Metabolic control of circulation. Effects of iodoacetate and fluoroacetate. J Clin Invest 60: 61, 1977

5. Peuler JD, Johnson GA: Simultaneous single isotope radioenzymatic assay of plasma norepinephrine, epinephrine and dopamine. Life Sci 21: 625, 1977

6. Winer BJ: Statistical Principles in Experimental Design, Ed 2, McGraw-Hill, New York, $\mathrm{P} 261,1971$

7. Dunnett CW: New tables for multiple comparisons with a control. Biometrics 20:482, 1964

8. Karlsberg RP, Penkoske PA, Cryer PE, Corr PB, Roberts R: Rapid activation of the sympathetic nervous system following coronary artery occlusion: relationship to infarct size, site, and haemodynamic impact. Cardiovasc Res 13: 523, 1979

9. Ceremużyński L: Hormonal and metabolic reactions evoked by acute myocardial infarction. Circ Res 48: 767, 1981

10. McDonald L, Baker C, Bray C, McDonald A, Restieaux N: Plasma-catecholamines after cardiac infarction. Lancet 2: 1021, 1969

11. Staszewska-Barczak J: The reflex stimulation of catecholamine secretion during the acute stage of myocardial infarction in the dog. Clin Sci 41 : 419, 1971

12. Kliks BR, Burgess MJ, Abildskov JA: Influence of sympathetic tone on ventricular fibrillation threshold during experimental coronary occlusion. Am J Cardiol 36: 45, 1975

13. Goldberg LI: Cardiovascular and renal actions of dopamine: Potential clinical applications. Pharmacol Rev 24: 1, 1972

14. Iversen LL: Catecholamine uptake processes. Br Med Bull 29: 130, 1973

15. Nash CW, Wolff SA, Ferguson BA: Release of tritiated noradrenaline from perfused rat hearts by sympathomimetic amines. Can J Physiol Phamacol 46: 35, 1968

16. Hinds JE, Hawthorne EW: Comparative cardiac dynamic effects of dobutamine and isoproterenol in conscious instrumented dogs. Am J Cardiol 36: 894, 1975

17. Vatner SF, Baig H: Importance of heart rate in determining the effects of sympathomimetic amines on regional myocardial function and blood flow in conscious dogs with acute myocardial ischemia. Circ Res 45: 793, 1979

18. Tuttle RR, Mills J: Dobutamine. Development of a new catecholamine to selectively increase cardiac contractility. Circ Res 36: 185, 1975

19. Robie NW, Nutter DO, Moody C, McNay JL: In vivo analysis of adrenergic receptor activity of dobutamine. Circ Res 34: 663, 1974

20. Gillespie TA, Ambos HD, Sobel BE, Roberts R: Effects of dobutamine in patients with acute myocardial infarction. Am J Cardiol 39: 588, 1977 